\title{
Aulas de ciências para surdos: estudos sobre a produção do discurso de intérpretes de LIBRAS e professores de ciências
}

\author{
Science classes for deaf students: studies on the production \\ of discourse by interpreters of LIBRAS and science teachers
}

Walquíria Dutra de Oliveira ${ }^{1}$ - Anna Maria Canavarro Benite ${ }^{2}$

\begin{abstract}
Resumo: O bilinguismo na educação de surdos pressupõe a língua de sinais como primeira língua do surdo e, com a inclusão escolar, os alunos surdos foram inseridos em instituições regulares de ensino, implicando uma nova estrutura da sala de aula. O ensino de ciências para surdos é um desafio, pois o aluno surdo utiliza uma língua diferente da do professor, e necessita de um intérprete de LIBRAS para ter acesso ao corpo de conhecimentos mediados por ele. A investigação objetivou analisar a produção de narrativas (um gênero do discurso) de professores e intérpretes de LIBRAS sobre a aula de ciências para surdos. As narrativas foram produzidas no "diário de aula", e foram analisadas pela técnica de análise de conteúdo. Nossos resultados apontam que o bilinguismo ainda não permeia a sala de aula inclusiva, e que a barreira linguística é a maior dificuldade encontrada no aprendizado dos conhecimentos científicos pelos alunos surdos.
\end{abstract}

Palavras-chave: Ensino de ciências. Surdos. LIBRAS. Narrativa. Bilinguismo.

\begin{abstract}
Bilingualism in deaf education presumes sign language as the first language of the deaf. With school inclusion deaf students have been enrolled in regular educational institutions resulting in a new structure in the classroom. Science teaching for the deaf is a challenge, because the student uses a language that is different from the teacher and needs a LIBRAS interpreter to access the body of knowledge mediated by the interpreter. The present study investigated the production of narratives (as a discourse genre) of professors and LIBRAS interpreters in science classes for deaf students. The narratives were produced in the class diary and analyzed by the content analysis technique. Our results pointed out that bilingualism still does not pervade the inclusive classroom, and the language barrier is the major difficulty found in learning science by deaf students.
\end{abstract}

Keywords: Science teaching. Deaf. Brazilian Language of Signals. Narrative. Bilinguism.

\footnotetext{
${ }^{1}$ Universidade Federal de Goiás (UFG), Rua Riachuelo, 1530, CEP 75804-020, Jataí, GO, Brasil. E-mail: <walquiriadutra@outlook.com>

${ }^{2}$ Instituto de Química, Universidade Federal de Goiás (UFG), Goiânia, GO, Brasil.
} 


\section{Introdução}

Na história da educação de surdos, três filosofias foram difundidas: o oralismo, a comunicação total e o bilinguismo. Atualmente, o bilinguismo é a filosofia mais aceita, apesar de as três coexistirem. Esta filosofia reconhece a língua de sinais como língua materna do surdo, e pressupõe o aprendizado do português como segunda língua.

Diante da perspectiva da inclusão escolar, a educação de surdos, que antes acontecia, geralmente, em escolas especiais, passa a se dar em escolas regulares. Por sua vez, na escola regular, o aluno surdo passa a ter contato com os conhecimentos científicos que lhe são apresentados pelo professor de ciências em língua portuguesa. Dessa forma, o aluno surdo que não utiliza essa língua, necessita da atuação de um intérprete da Língua Brasileira de Sinais (LIBRAS). Segundo Hodson (1982), a natureza das ciências pressupõe um conjunto de conhecimentos únicos, dotado de uma linguagem simbólica, social e historicamente construída. Então, aprender ciências é ser alfabetizado nessa linguagem. Neste cenário, nos salta a inquietação: como está acontecendo o ensino de ciências para surdos?

Se o conhecimento científico deve ser alvo de aprendizado de todos - princípios estes norteados pela alfabetização científica (CACHAPUZ et al., 2005; CHASSOT, 2003), então, ele deve ser alvo de aprendizado, também, dos alunos surdos, para que possam exercer sua cidadania. De modo que, elucidar como está acontecendo o ensino de ciências para surdos dentro do paradigma da inclusão escolar é de suma importância para revelar aspectos relativos ao ensino-aprendizado dos conceitos científicos para esses sujeitos.

\section{Sobre a surdez e o ensino de ciências}

Inicialmente, acreditava-se que os sujeitos surdos eram incapazes de aprender; posteriormente, com a institucionalização do atendimento, sua forma de linguagem foi banida das instituições escolares por muito tempo (CAPOVILLA, 2000; LACERDA, 1998).

Só recentemente, com a adoção do bilinguismo e investimentos em pesquisas sobre a língua de sinais, é que as formas de expressão e comunicação dos surdos foram reconhecidas. A comunicação total muito contribuiu para este momento da educação de surdos, pois foi por meio dessa filosofia que se começou a admitir a língua de sinais como meio de aprendizado e comunicação do sujeito surdo (LORENZINI, 2004).

No paradigma da inclusão escolar, os surdos têm sido inseridos nas escolas regulares. Mas será que esses alunos estão conseguindo aprender ciências? Para responder a esta pergunta, precisamos compreender alguns aspectos da formação de conceitos por esses sujeitos.

Segundo Vigotsky (2000), quando a criança ouvinte chega à escola, já tem conceitos espontâneos formados. Já a criança surda, devido à falta de língua constituída, ingressará no ambiente escolar sem esses conceitos, já que são, em sua maioria, filhos de pais ouvintes. Desta forma, a aquisição da língua oral nas pessoas surdas estará prejudicada (LACERDA, 2006) e o atraso na linguagem pode trazer consequências emocionais, sociais e cognitivas, mesmo com o aprendizado tardio de uma língua. Assim, 
[...] devido às dificuldades acarretadas pelas questões de linguagem, observa-se que as crianças surdas encontram-se defasadas no que diz respeito à escolarização, sem o adequado desenvolvimento e com um conhecimento aquém do esperado para sua idade. (LACERDA, 2006, p. 165)

Este fator dificulta bastante o acesso do aluno surdo ao conhecimento científico, pois é por intermédio dos conceitos espontâneos que o aluno terá condições de se apropriar e formar os conceitos científicos. Ainda, segundo o autor, no processo de formação de conceitos, o signo é a palavra e, em princípio, tem função de mediar a formação de um conceito, e, depois, se torna seu símbolo.

A formação do conceito e aquisição de sentido se dá por meio da palavra. Vigotsky (2000) afirma que o processo de formação de conceitos pressupõe o próprio processo de domínio da linguagem, do uso da palavra ou signo para mediar os processos psicológicos:

O conceito é impossível sem palavras, o pensamento em conceitos é impossível fora do pensamento verbal; em todo esse processo, o momento central, que tem todos os fundamentos para ser considerado causa decorrente do amadurecimento de conceitos, é o emprego específico da palavra, o emprego funcional do signo como meio de formação de conceitos. (VIGOTSKY, 2000, p. 170)

Para a criança surda, o signo linguístico será o sinal da LIBRAS. Entretanto, segundo Santana (2007), 90\% dos surdos são filhos de pais ouvintes e, portanto, dificilmente terão língua constituída, de forma que não irão adquirir nem o português, nem a LIBRAS antes do processo de escolarização. Este diagnóstico é diferente para as crianças surdas filhas de pais surdos, cujo desempenho linguístico na aquisição da LIBRAS é comparado ao da aquisição da linguagem oral pelos ouvintes (SANTANA, 2007).

O signo linguístico para a criança surda sem língua constituída será formado por elementos visuais (sinais domésticos/família), mas que não são compartilhados pelos membros da comunidade (de surdos) nem a comunidade em que vive (ouvintes), ou seja, essa criança desenvolve uma linguagem baseada nos aspectos visuais, mas sem estrutura de uma língua. De forma que, neste estudante, de acordo com Vigotsky (2000, p. 216), “está ausente a causa principal que leva à formação de pseudoconceitos infantis".

Segundo o autor, no processo de formação de conceitos pelo surdo, "a criança não forma complexos livremente combinando objetos em grupos integrais, mas que ela já encontra no discurso dos adultos, palavras vinculadas a determinados grupos de referentes" (VIGOTSKY, 2000, p. 217). Assim, as crianças surdas, entregues a si mesmas, formam livremente os complexos que serão representados por uma mesma palavra, neste caso, estas palavras seriam representações visuais como expressões e sinais “domésticos” (VIGOTSKY, 2000).

$\mathrm{Na}$ escola, quando os alunos estudam o conceito da palavra "bactéria", por exemplo, os ouvintes provavelmente já têm algum conceito espontâneo sobre essa palavra: situações cotidianas de quando a mãe fala que o filho tem de lavar as mãos para não se contaminar, não entrar em contato com germes, por exemplo, podem levar esse aluno a remeter o conceito 
de bactérias às doenças. A palavra "bactéria" já terá algum significado para essa criança, e é a partir desse significado que ele irá compreender o conceito científico de bactéria, tal como um micro-organismo, sem núcleo delimitado e DNA não organizado, com suas formas de reprodução e disseminação.

Lacerda (2009) também compreende que a linguagem tem função primordial na construção de conceitos, e que é a palavra um meio para essa construção. Nas crianças surdas, sem acesso à linguagem oral, a construção de conhecimentos e a apropriação da cultura ouvinte estarão comprometidas, e a escola deve estar atenta a isso. Pois:

No caso dos alunos surdos, o contato com essa língua/linguagem dependerá da presença de usuários de LIBRAS - sua língua de acesso à linguagem - e em muitos contextos educacionais, fundamentalmente, da presença do intérprete de LIBRAS, para mediar relações dialógicas entre interlocutores de línguas diferentes. (LACERDA, 2009, p. 7)

Desta forma, o aluno surdo, sem língua constituída, sem conceitos espontâneos formados, ingressará num ambiente no qual terá de: constituir sua língua, aprender outra língua, formar conceitos espontâneos, e ser iniciado na aquisição de conceitos científicos dentro de um mesmo período de tempo.

\section{Das opções metodológicas}

Constituída por elementos de uma pesquisa participante (BRANDÃO, 1984), esta investigação nasce dentro da própria comunidade dos sujeitos envolvidos, na possibilidade de pensar e intervir no grupo social investigado, para dar voz a este. As pesquisadoras são membros das duas comunidades envolvidas: deficientes auditivos e professores de ciências. Nesse sentido, compreender a condição de deficiente auditiva da pesquisadora, é compreender os conceitos, métodos e instrumentos aqui utilizados, por meio de sua trajetória sociotemporal.

Por intermédio do instrumento de coleta de dados "diários de aula" de Zabalza (2004), professores de ciências (P1, P2, P3...) e intérpretes de LIBRAS (ILS1, ILS2, ILS3...) foram convidados a narrar o cotidiano da sala de aula inclusiva, evidenciando aspectos do processo de ensino e interpretação/tradução do conhecimento científico para alunos surdos. As narrativas não necessariamente deveriam ser uma atividade diária, podendo ser tecidas em qualquer dia ou horário, desde que, no prazo de uma semana, mesmo que os sujeitos não narrassem todos os dias, as narrativas deveriam, sempre que possível, se referir a todas as aulas e acontecimentos da semana em questão.

Ao final de cada semana, os diários eram recolhidos pelas pesquisadoras (Pq), e diálogos eram estabelecidos por meio do instrumento de coleta de dados, no intuito de direcionar a pesquisa e investigar elementos que ficaram implícitos nas narrativas apresentadas.

No começo de outra semana, os diários eram devolvidos aos sujeitos da investigação e estes faziam novas narrativas e davam retorno aos diálogos estabelecidos, o que consistiu num ciclo contínuo durante um ano. A coleta de dados aconteceu entre o período de 2009 a 2010, em que escolas foram convidadas a participar desta investigação. 
A amostra pesquisada pode ser caracterizada segundo os critérios: (1) o caráter volitivo; (2) existência de alunos surdos; (3) e presença de intérpretes destinados a estes alunos - e está apresentada no Quadro 1.

Quadro 1. O cenário da investigação

\begin{tabular}{|c|c|c|c|c|}
\hline Ano & Escola & $\begin{array}{c}\text { Professores } \\
\text { e intérpretes }\end{array}$ & Alunos & $\begin{array}{c}\text { Total de aulas } \\
\text { narradas }\end{array}$ \\
\hline 2009 & $\begin{array}{c}\text { Escola A - Escola de porte médio situado } \\
\text { no centro da capital. }\end{array}$ & P1 & A4, A5, A6 e A7 & 21 \\
\cline { 2 - 5 } 2010 & $\begin{array}{c}\text { P2 e ILS2 } \\
\text { Escola B - Escola de médio porte }\end{array}$ & P3 e ILS3 & A2 e A3 & 03 \\
\cline { 2 - 5 } & $\begin{array}{c}\text { Escolizada na periferia da capital. } \\
\text { na parte central da cidade de Jataí - Goiás. }\end{array}$ & P4 e ILS4 & A8 e A9 & 09 \\
\hline
\end{tabular}

Fonte: Elaborado pelos autores.

Apresentamos, aqui, o recorte de quatro aulas (01 a 04) ministradas por P3 e interpretadas por ILS3 no $5^{\circ}$ ano do Ensino Fundamental, com a presença de um aluno surdo (A1) na Escola B. E uma aula ministrada (01) por P2 e interpretada por ILS2, no $6^{\circ}$ ano do Ensino Fundamental, onde estavam presentes dois alunos surdos (A2 e A3), na Escola A, conforme o Quadro 2.

Quadro 2. Situando a produção de narrativas de acordo com o tema das aulas de ciências

\begin{tabular}{|c|c|c|c|}
\hline Sujeitos & $\mathbf{N}^{\text {o } a u l a}$ & Dia & Temática da aula \\
\hline P2 e ILS2 & 01 & $08 / 06 / 2009$ & Cadeia alimentar \\
& 02 & $12 / 06 / 2009$ & $\begin{array}{c}\text { Cadeia alimentar } \\
\text { Cadeia alimentar }\end{array}$ \\
\hline \multirow{5}{*}{ P3 e ILS3 } & 03 & $15 / 06 / 2009$ & Sistema solar \\
& 01 & $05 / 03 / 2010$ & Sistema solar \\
& 02 & $08 / 03 / 2010$ & Sistema solar \\
& 03 & $22 / 03 / 2010$ & Sistema solar \\
& 05 & $13 / 04 / 2010$ & Ar \\
& 06 & $26 / 04 / 2010$ & Ar \\
& 07 & $10 / 05 / 2010$ & Ar \\
& 08 & $17 / 05 / 2010$ & Ar \\
& 09 & $20 / 06 / 2010$ & Ar \\
\hline
\end{tabular}

Fonte: Elaborado pelos autores. 
Os resultados foram analisados pela técnica de análise de conteúdo (BARDIN, 2008), análise temática, com a criação de categorias a posteriori, produto de convergência das narrativas dos sujeitos desta investigação.

Importa informar que, nesta técnica de análise, tira-se partido do tratamento das mensagens para inferir, por meio da descrição (enumeração das características do texto) e da interpretação (significação concedida a essas características). A inferência é um processo intermediário entre essas duas ações, revelando as causas, os efeitos e consequências dos atos enunciativos dos envolvidos (BARDIN, 2008).

\section{Aulas de ciências: análise do discurso de professores e intérpretes de LIBRAS}

As narrativas foram produzidas em diários individuais, ou seja, os professores e intérpretes narraram em diários diferentes e tiveram privacidade em suas produções discursivas, assim, o professor não sabia o que o intérprete estava a narrar, nem o contrário aconteceu.

Apresentaremos os resultados referentes às narrativas de professores e intérpretes sobre uma mesma aula. O Quadro 3 apresenta a produção do discurso referente às aulas $n^{\circ} 01$, 02, 03 e 04, ministradas por P3 e interpretadas por ILS3, com o tema "Sistema Solar", onde estava presente um aluno (A1).

A narrativa produzida por P3, na primeira aula sobre o tema, demonstra que essa professora tenta estabelecer diálogo entre o conhecimento científico que representa e os conceitos espontâneos que seus alunos (construídos em seus contextos sociais) trazem para a aula de ciências: "P3: No meu primeiro momento com a turma, o objetivo era levantar os conbecimentos prévios para tê-los como ponto de partida no planejamento dos conteúdos e metodologias". [Aula 1, Quadro 3]

Importa lembrar que, no processo de transposição didática, o conhecimento científico adquire significação e começa a ser mais utilizado do que o conhecimento espontâneo, por conta de suas características, tais como: ser um conhecimento crítico, sistematizado, que resiste à argumentação. Dessa forma, esse resultado parece inferir que P3 se preocupa com o processo de significação.

O discurso de P3 se refere a sua relação com o aluno surdo:

P3: Quando iniciei com o livro, falando sobre o sistema solar, notei que ele estava com dificuldade em compreender. Planejei então para os próximos encontros, mostrar uma maquete do sistema solar e o funcionamento e apresentar um filme informativo sobre o tema. [...] Estamos pensando em levá-lo ao Planetário, vamos buscar uma forma adequada de fazê-lo. [Aula 1, Quadro 3]

Esse resultado denota que P3 reflete sobre sua ação quando planeja a partir da aula anterior e utiliza diferentes materiais didáticos; não desconsiderando a heterogeneidade presente na sala de aula de ciências. Importa dizer que os diferentes materiais e estratégias didáticas elencadas por P3, para o replanejamento de sua ação, têm relação direta com o sentido da visão, o que nos parece ser acertado, uma vez que estreita os laços dos alunos surdos com sua primeira língua, que é gestual-visual, e não foge dos referenciais visuais que, majoritariamente, ocupam a sala de aula de ciências, tais como: quadro e giz, prova escrita, tabelas, gráficos, figuras e ilustrações. 
Quadro 3. Narrativas de P3 e ILS3 sobre as aulas de ciências com temática de "Sistema Solar"

\begin{tabular}{|c|c|c|}
\hline Aula & P3 & ILS3 \\
\hline 01 & $\begin{array}{l}\text { O ensino de ciências requer muita curiosidade e uma perfeita } \\
\text { compreensão dos temas estudados. Logo, o canal de comunicação } \\
\text { não pode ser falho, para que o aluno não se sinta perdido. No } \\
\text { meu primeiro momento com a turma, o objetivo era levantar } \\
\text { os conhecimentos prévios para tê-los como ponto de partida no } \\
\text { planejamento dos conteúdos e metodologias. [...] Quando iniciei } \\
\text { com o livro, falando sobre o sistema solar, notei que ele estava com } \\
\text { dificuldade em compreender. Observei que por mais que a intérprete } \\
\text { se esforçasse, uma aula teórica, um tema abstrato, fora do seu } \\
\text { "mundinho" limitado, não surtiria nunca os efeitos desejados. Planejei } \\
\text { então para os próximos encontros, mostrar uma maquete do sistema } \\
\text { solar e o funcionamento e apresentar um filme informativo sobre o } \\
\text { tema. [...] Observei que o aluno não é bem assistido pela família, } \\
\text { que ninguém em casa se comunica com ele em LIBRAS e que nem a } \\
\text { medicação da qual ele necessita, Ihe é dada corretamente. Conclui que } \\
\text { o rendimento do aluno, depende de aulas vivenciadas concretamente e } \\
\text { muito bem planejadas. Que depende também de um maior empenho } \\
\text { familiar no intuito de ajudá-lo. Estamos pensando em levá-lo ao } \\
\text { Planetário, vamos buscar uma forma adequada de farế-lo. }\end{array}$ & $\begin{array}{l}\text { O grande problema, talvez. o } \\
\text { maior de todos, é que o A1 } \\
\text { não é alfabetizado, sabe poucas } \\
\text { palavras e é terrivelmente inquieto } \\
\text { mas, apesar de tudo gosto demais } \\
\text { de trabalhar com ele [...] Hoje } \\
\text { comescamos a aprender o sistema } \\
\text { solar e ele ficou muito interessado } \\
\text { no assunto. Queria levá-lo ao } \\
\text { planetário mas a coordenadora } \\
\text { me disse que a verba para levá-los } \\
\text { está bem longe de chegar por aqui } \\
{[. . .] \text { A verdade é que eu não }} \\
\text { dou conta sozinha de ajudá-lo a } \\
\text { aprender tudo. Se a mãe dele me } \\
\text { ajudasse, eu "salvaria o mundo". }\end{array}$ \\
\hline 02 & $\begin{array}{l}\text { Quando tento levantar os conhecimentos prévios dos alunos, lanço } \\
\text { uma ideia, ou um tema a ser estudado e deixo que cada um expresse } \\
\text { os seus conhecimentos, tecendo uma rede de ideias dos alunos. No } \\
\text { caso do aluno surdo, a professora intérprete serve de ponte para me } \\
\text { passar o que ele pensa sobre o tema em debate. Porém, não foi e não } \\
\text { é o que acontece em nossas aulas. A intérprete dir que ele sabe muito } \\
\text { pouco de LIBRAS e não se interessa em expor suas ideias. [...] O } \\
\text { conhecimento acontece por meio de desafios e estímulos, e aí o papel } \\
\text { da comunicaşão é fundamental. Um aluno que não ouve, não faz. } \\
\text { leitura labial e mal conbece a Lingua dos Sinais, fica limitado. Vejo-o } \\
\text { agressivo, inquieto e totalmente desinteressado e compreendo que ele é o } \\
\text { unico que não tem culpa nessa situação absurda. }\end{array}$ & $\begin{array}{l}\text { Hoje a professora levou o sistema } \\
\text { solar para a sala, foi muito bom, } \\
\text { pois ele viu e teve uma ideia de } \\
\text { espaço... na questão do surdo, ver é } \\
\text { mais do que falar. }\end{array}$ \\
\hline
\end{tabular}

continua

Ainda, P3 narra sobre estreitar essa relação quando discorre sobre a relação de A1 com a família, fato que revela que a escola é instituição composta não só por professores e alunos, mas pela comunidade.

P3: Observei que o aluno não é bem assistido pela família, que ninguém em casa se comunica com ele em LIBRAS e que nem a medicação da qual ele necessita, the é dada corretamente. Conclui que o rendimento do aluno, depende de aulas vivenciadas concretamente e muito bem planejadas. Que depende também de um maior empenho familiar no intuito de ajudá-lo. [Aula 1, Quadro 3] 
Quadro 3. continuação

\begin{tabular}{|c|c|c|}
\hline Aula & P3 & ILS3 \\
\hline 03 & $\begin{array}{l}\text { Propus que eles respondessem as questoes do livro sobre } \\
\text { o sistema solar. }\end{array}$ & $\begin{array}{l}\text { Quando a professora entrou na sala com o } \\
\text { sistema solar concreto, ele encheu os olhos. Hoje } \\
\text { perguntei quantos planetas tem o sistema solar } \\
\text { e ele me respondeu que havia 9. Eu queria } \\
\text { bater palmas de felicidade... Tenho certeza que } \\
\text { ele aprendeu isso pelo fato dela ter levado algo } \\
\text { mais concreto pois, se eu tivesse apenas falado, } \\
\text { ele não teria lembrado. [...] A aula de ciências } \\
\text { parece estar rendendo, temos um trabalho sobre } \\
\text { aquecimento global e uma prova para quinta } \\
\text { feira. }\end{array}$ \\
\hline 04 & $\begin{array}{l}\text { O nosso aluno em questão parece mais calmo esses dias. } \\
\text { Percebo um vinculo muito forte entre ele e a professora } \\
\text { intérprete, porém não vejo o brilho do interesse pelas } \\
\text { aulas nascer em seus olhos. Percebo onde estão as falhas, } \\
\text { mas não sei como mudar uma realidade que parece mais } \\
\text { camisa de força, sufocando os nossos anseios por uma } \\
\text { educação de qualidade. [...] A escola só será interessante } \\
\text { para os alunos quando ela fizer sentido na vida deles, } \\
\text { quando eles acreditarem nela. }\end{array}$ & $\begin{array}{l}\text { Hoje tem prova de ciências, terça-feira eu estudei } \\
\text { junto com ele. Peguei algumas palavras chaves } \\
\text { como: satélite, meteoro... e fiz ele "decorar" o } \\
\text { conceito. Expliquei bastante para que ele pelo } \\
\text { menos saiba identificar alguma coisa na prova. } \\
\text { [...] a prova de ciências saiu tudo como planejado. } \\
\text { Ele soube identificar as palavras e me responder } \\
\text { o conceito. }\end{array}$ \\
\hline
\end{tabular}

Fonte: Elaborado pelos autores.

Nossos resultados, também, remontam à não-relação que parece haver entre professor e intérprete: "P3: Observei que por mais que a intérprete se esforçasse, uma aula teórica, um tema abstrato, fora do seu "mundinho" limitado, não surtiria nunca os efeitos desejados". [Aula 1, Quadro 3]

P3, em sua narrativa, aponta o não-domínio da linguagem científica por ILS3, se reconhecendo como representante desse conhecimento. Defendemos que é o professor de ciências o representante da comunidade científica na sala de aula, e o responsável pela mediação desse conhecimento. Nossos resultados permitem inferir que, no caso do aluno surdo, essa mediação estará intermediada pelo intérprete de libras, que não domina esses conhecimentos e, mesmo assim, deve fazer uma interpretação das mensagens enunciadas pelo professor.

Segundo Vigotsky (2003), a criança estabelece seus conceitos por meio da relação com a comunidade em que vive. Dessa forma, a construção dos conceitos científicos se dá por intermédio da mediação de membros mais experientes da comunidade científica: os professores de ciências. Se o aluno surdo tem sua relação restrita ao ILS, o aprendizado dos conceitos científicos fica prejudicado, já que o intérprete não domina esses conhecimentos.

Interessante observar que, mesmo narrando com total privacidade, as narrativas de ILS3 pontuam os mesmos problemas narrados por P3: 
ILS3: O grande problema, talvezo o maior de todos, é que o A1 não é alfabetizado, sabe poucas palavras e é terrivelmente inquieto mas, apesar de tudo gosto demais de trabalhar com ele [...] Hoje comecamos a aprender o sistema solar e ele ficou muito interessado no assunto. Queria levá-lo ao planetário mas a coordenadora me disse que a verba para levá-los está bem longe de chegar por aqui. [Aula 1, Quadro 3]

ILS3 percebe a barreira linguística como fator crucial no aprendizado do surdo e discorre sobre a dificuldade do aluno com o conteúdo "sistema solar". Além do não-domínio dos conhecimentos científicos pelo intérprete de libras, ILS3 observa, ainda, que o aluno surdo (A1) não é bem alfabetizado. A falta de linguagem constituída por esse aluno faz com que este não compartilhe os signos linguísticos utilizados pelos ILS e nem pelos professores de ciências, o que compromete seu aprendizado. Além disso, a falta de linguagem constituída impossibilita a formação de conceitos por esses alunos, sejam eles espontâneos e/ou científicos, já que, segundo Vigotsky (2003), é por meio da linguagem que o conhecimento é formado a partir da relação com o mundo exterior.

$\mathrm{Na}$ segunda aula sobre o tema, P3 leva uma maquete do sistema solar e ministra sua aula com base nesse modelo para melhor entendimento dos alunos sobre o conteúdo. Nessa aula, a professora relata a dificuldade no levantamento dos conhecimentos prévios do aluno surdo, devido à barreira linguística e a não-alfabetização deste aluno em ambas as línguas presentes na sala, o que converge com as narrativas de ILS3. Além disso, P3 narra sua preocupação devido a esta barreira linguística do aluno surdo, e o vê limitado e desinteressado frente ao conteúdo. Nessa mesma aula, ILS3 elogia a demonstração feita por P3 na maquete sobre sistema solar e reconhece esse recurso como essencial para o aprendizado do aluno surdo:

P3: Quando tento levantar os conbecimentos prévios dos alunos, lanço uma ideia, on um tema a ser estudado e deixo que cada um expresse os seus conbecimentos, tecendo uma rede de ideias dos alunos. No caso do aluno surdo, a professora interprete serve de ponte para me passar o que ele pensa sobre o tema em debate. Porém, não foi e não é o que acontece em nossas aulas. A intérprete dir que ele sabe muito pouco de LIBRAS e não se interessa em expor suas ideias. [...] O conbecimento acontece por meio de desafios e estímulos, e ai o papel da comunicação é fundamental. Um aluno que não ouve, não faz leitura labial e mal conhece a Lingua dos Sinais, fica limitado. [Aula 2, Quadro 3]

ILS3: Hoje a professora levon o sistema solar para a sala, foi muito bom, pois ele viu e teve uma ideia de espaço... na questão do surdo, ver é mais do que falar. [Aula 2, Quadro 3]

Importante observar que ambos os sujeitos (ILS3 e P3) fazem considerações, elogios e críticas sobre o trabalho que o outro realiza. Na terceira aula, a professora P3 narra sobre a proposta de atividades do livro didático sobre o sistema solar, a ser realizada pelos alunos. ILS3 narra, ainda, seu entusiasmo frente à maquete do sistema solar explorada pela professora; enfatiza a necessidade de se trabalharem questões concretas com os alunos surdos, e parece estar 
muito envolvida com as aulas de ciências, tanto que se refere, aos trabalhos a serem realizados pelo aluno surdo, como "seus", tal como transcrito a seguir:

P3: Propus que eles respondessem as questões do livro sobre o sistema solar. [Aula 3, Quadro 3]

ILS3: Quando a professora entrou na sala com o sistema solar concreto, ele enchen os olhos. [...] A aula de ciências parece estar rendendo, temos um trabalho sobre aquecimento global e uma prova para quinta-feira. [Aula 3, Quadro 3]

Por sua vez, P3 não constrói argumentações sobre as dificuldades encontradas na resolução das questões do livro pelos alunos surdos, talvez devido às características de sua relação com esses alunos, que têm uma relação mais estreita com ILS3. Já ILS3, narra com entusiasmo, e comemora, apesar de não reconhecer a especificidade simbólica desse conhecimento.

Por fim, na quarta aula sobre o tema "Sistema solar", a professora aplica uma prova como instrumento de avaliação de seus alunos. Sobre essa aula, P3 não se remete à aplicação da prova, mas se concentra em analisar aspectos relativos ao aluno e sua relação com a intérprete de LIBRAS. P3 admite o vínculo entre aluno surdo e intérprete, mas lamenta não ver, no aluno surdo, "o brilho do interesse pelas aulas nascer em seus olhos" (P3, Quadro 3). ILS3 narra o estudo realizado com o aluno surdo antes da prova, para que ele "decorasse" os conceitos e "para que a prova saísse como planejado" (Quadro 3). Cabe considerar as limitações que as posições definidas nesta relação impõem a seus sujeitos. Ora, P3 não conhece/domina a LIBRAS, e não estabelece contato com seu aluno surdo; ILS3 não domina o conhecimento científico, e A1 não está bem alfabetizado.

Os resultados sugerem que, ao lançar mão dessa estratégia de memorização de conceitos, ILS3 revela a compreensão de conceito como rótulo (TEIXEIRA, 2006), ou seja, um conjunto de atributos ou propriedades perceptíveis que caracterizam um conceito. Nesse caso, os referentes que constituem determinado termo que nomeia dado objeto e/ou fato estão no mundo real; não são ideias. Concordamos com Teixeira (2006), quando este tece críticas à concepção de conceitos como rótulo, pois existem fatos e objetos que, para serem entendidos, necessitam mais do que a simples identificação de atributos. Compreendemos que este é o caso dos fenômenos e objetos trabalhados por ILS3, que são extremamente abstratos e não são o domínio de ILS3.

No Quadro 4, apresentamos as narrativas sobre a aula $\mathrm{n}^{\circ}$ 01, ministrada por P2 e interpretada por ILS2, com o tema "Cadeias alimentares". Foram três as aulas sobre o tema, entretanto, apresentaremos apenas análise da primeira. Estavam presentes dois alunos surdos (A2, A3).

Nessa aula, a professora de ciências faz o levantamento dos conhecimentos prévios dos alunos, apresenta o conteúdo e realiza atividades sobre o mesmo. P2 utiliza vários recursos didáticos para apresentar o conteúdo, e percebe que os alunos surdos têm dificuldades em compreendê-lo, mesmo que ela utilize uma linguagem simples e eles pareçam ter afinidade com a disciplina de ciências. A professora reconhece que esta dificuldade está ligada à barreira linguística vivida pelo aluno surdo e reconhece que eles não estão completamente alfabetizados: "P2: Devo ressaltar que os alunos DA foram mais lentos para entenderem as explicações, embora eu tenha 
Quadro 4. Narrativas de P2 e ILS2 sobre a aula de ciências com temática de "Cadeias alimentares"

\begin{tabular}{|c|c|c|}
\hline Aula & P2 & ILS2 \\
\hline 01 & 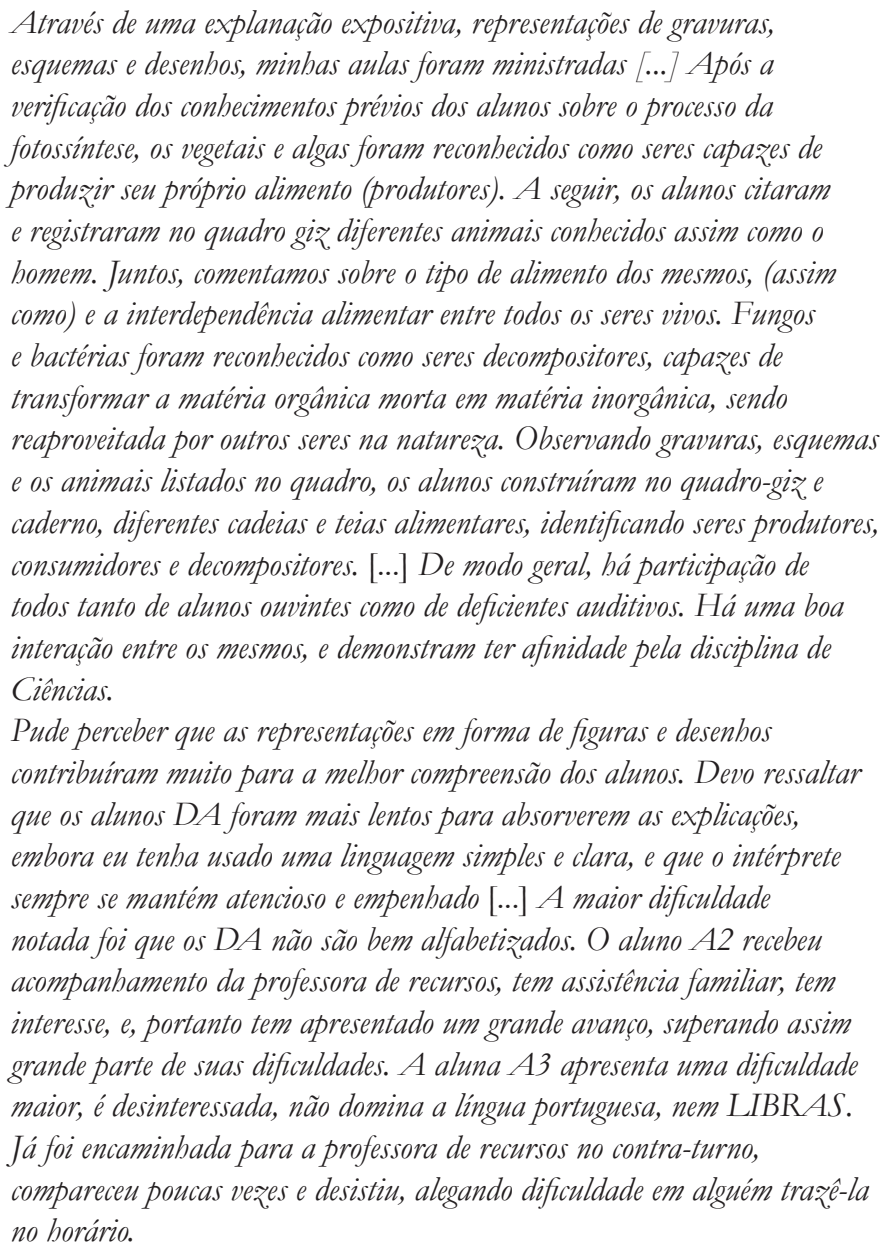 & $\begin{array}{l}\text { A professora se esforça muito } \\
\text { para explicar o conteúdo } \\
\text { para os alunos. Além de } \\
\text { passar o conteúdo no quadro, } \\
\text { ela explica usando desenhos } \\
\text { no quadro, e as ilustrações } \\
\text { do livro. Falando sobre } \\
\text { alunos deficientes auditivos } \\
\text { eles encontram uma certa } \\
\text { dificuldade na compreensão } \\
\text { do conteúdo pelos seguintes } \\
\text { motivos: } 1^{\circ} \text { não dominam } \\
\text { LIBRAS, } 2^{\circ} \text { encontram } \\
\text { muita dificuldade para } \\
\text { memorizar palavras, } 3^{\circ} \\
\text { conhecem muito pouco os } \\
\text { significados das palavras em } \\
\text { português. [...] a tradução } \\
\text { do conteúdo é facilitada } \\
\text { usando ilustraçoes do livro } \\
\text { e os desenhos usados no } \\
\text { quadro. O desenho que } \\
\text { representa a fotossintese } \\
\text { e as cadeias alimentares, } \\
\text { por exemplo, ajudam de } \\
\text { forma significativa o surdo a } \\
\text { compreender o que está sendo } \\
\text { explicado. }\end{array}$ \\
\hline
\end{tabular}

Fonte: Elaborado pelos autores.

usado uma linguagem simples e clara, e que o intérprete sempre se mantém atencioso e empenhado [...] A maior dificuldade notada foi que os DA não são bem alfabetizados" [Aula 1, Quadro 4].

O P2, assim como P3, reconhece que não ser alfabetizado interfere no aprendizado dos conteúdos. A produção dessa argumentação denota que P2 desconhece as características linguísticas destes alunos, ao admitir utilizar "linguagem simples e clara" como requisito para facilitar a aprendizagem de surdos.

Entretanto, P2 reconhece, também, que o aluno surdo que recebeu um acompanhamento especializado e apoio da família (A2) tem mais facilidade no aprendizado, superando suas dificuldades. Já a aluna A3, citada por P2 (Aula 1, Quadro 4), que não tem atendimento 
especializado, não domina LIBRAS nem português, parece não receber apoio da família e, nesse sentido, tem bastante dificuldade de aprendizado e se mostra desinteressada.

P2: O aluno $\mathbf{A} 2$ recebeu acompanhamento da professora de recursos, tem assistência familiar, tem interesse, e, portanto tem apresentado um grande avanço, superando assim grande parte de suas dificuldades. [Aula 1, Quadro 4]

O apoio da família é fundamental para o aluno surdo, já que maioria deles nasce em famílias ouvintes, sem contato com a LIBRAS. A forma como a família se posiciona em relação às diferenças do surdo poderá ajudar ou não no processo de aquisição da linguagem por parte deste. Caso a família ouvinte opte pelo não-aprendizado da LIBRAS e recursos médicos (como próteses, implantes cocleares etc., dependendo do caso) não estejam disponíveis para essa criança, ela ficará restrita aos sinais domésticos criados para a comunicação familiar e terá grandes dificuldades em sua escolarização.

Assim, os alunos surdos podem chegar à sala de aula sem língua constituída, e suas formas de comunicação são geralmente situadas pela comunicação não verbal. A sala de aula é um ambiente baseado na comunicação verbal, e isso acabará refletindo na apropriação do conhecimento (OLIVEIRA; MELO; BENITE, 2012).

ILS2, nesta aula, reconhece o esforço de P2 para apresentar o conteúdo aos alunos surdos, porque utiliza várias abordagens e recursos didáticos, porém, também reconhece a barreira linguística do aluno surdo. ILS2, assim como ILS3 (Quadro 3), reconhece que os alunos surdos não são completamente alfabetizados, tanto em português quanto em LIBRAS, e argumenta que os recursos visuais utilizados por P2 facilitam a interpretação/tradução do conteúdo ao aluno surdo.

ILS2: Falando sobre alunos deficientes auditivos eles encontram uma certa dificuldade na compreensão do conteúdo pelos seguintes motivos: $1^{\circ}$ não dominam LIBRAS, $2^{\circ}$ encontram muita dificuldade para memorizar palavras, $3^{\circ}$ conbecem muito pouco os significados das palavras em português. [...] a tradução do conteúdo é facilitada usando ilustrações do livro e os desenhos usados no quadro. [Aula 1, Quadro 4]

Os resultados expostos acima, a partir da convergência na produção de discurso sobre as aulas por P2, P3, ILS2 e ILS3, apontam para uma confusão de papéis entre professores e intérpretes, corroborando com os achados de Lacerda (2009) em suas pesquisas. Confusão esta que pode estar sendo evidenciada também devido à formação desses professores, e dos intérpretes de libras (que vem se dando em serviço). Vilela-Ribeiro e Benite (2010) constataram em sua pesquisa que a universidade não prepara os professores em formação inicial para a inclusão porque os próprios formadores não tiveram contato com esse assunto.

As aulas foram planejadas em português e a LIBRAS se tornou apenas um instrumento para dar acesso ao conteúdo ensinado pela professora. Assim, a LIBRAS não circulou efetivamente em sala como primeira língua para o surdo, representando um obstáculo para o acesso desse aluno. Em contrapartida, os ILS se sentiram responsáveis pelas dificuldades e incompreensões dos alunos surdos, assumindo para si a tarefa de ensinar, procurando formas alternativas de "passar" os conteúdos, e assumindo, de certa forma, o papel que seria dos professores. 
Queiroz, Silva e Macedo (2012, p. 121), em sua pesquisa, discutem as aulas de ciências para surdos

\begin{abstract}
Há necessidade de uma mudança pedagógica, é preciso mudar o foco no trabalho com os surdos, e esse trabalho deve ser centrado no desenvolvimento da linguagem, mas que não se resuma apenas à introdução da língua de sinais na escola. O ideal é que as escolas organizem o currículo partindo de uma perspectiva visual/espacial, e se o processo educacional ocorre mediante a interação linguística, deve ocorrer, portanto, na língua de sinais brasileira juntamente com outras experiências visuais, tais como língua portuguesa escrita, mímica/dramatização, figuras, recursos tecnológicos (vídeo/TV, slides, computador, retroprojetor) e leitura, desenvolvendo nos alunos a memória visual e o hábito de leitura; recebendo apoio de professor especialista conhecedor de língua de sinais, além de proporcionar intérpretes de Libras, para o maior acompanhamento das aulas.
\end{abstract}

Desta forma, "mudanças em vários aspectos da escolarização precisam ser atendidas no contexto da inclusão escolar, como currículo, organização escolar, avaliação, acessibilidade, entre outros" (OLIVEIRA, 2012, p. 69). Por meio da análise das narrativas, conseguimos inferir quatro pontos de convergência, entre professores e intérpretes, sobre a educação de surdos neste contexto, que representamos em quatro categorias de análise: (1) atribuem o não-aprendizado do aluno surdo à barreira linguística; (2) percebem que o aluno não foi alfabetizado; (3) os P e os ILS compartilham de raros contatos pontuais, sempre com intuito de ajudar o aluno surdo; (4) percebem ausência da família no processo de escolarização do aluno surdo.

Quando as professoras (P2 e P3) tentam levantar os conhecimentos prévios dos alunos, elas narram que essa atividade é dificultada, em primeiro lugar, pela barreira linguística existente entre eles, em que o surdo se comunica em uma língua e o professor em outra língua, de forma que o intérprete seria uma "ponte", como relatado por P3, para estabelecer a comunicação entre ambos. Em segundo lugar, essa atividade está comprometida pelo fato narrado tanto por professores quanto intérpretes, que é a não-alfabetização do surdo.

Os professores, sujeitos desta investigação, reconhecem que a disciplina de ciências requer compreensão de símbolos, e que o canal de comunicação não pode ser falho. ILS3, como não tem domínio desta linguagem científica, compreende o aprendizado dos conceitos como "decorar palavras", em que ela narra estudar com o aluno surdo, ensinar ciências a ele a partir de palavras do português, e isso é extremamente complicado, já que a mesma narra a não-alfabetização do aluno surdo em ambas as línguas presentes na sala de aula.

A utilização da língua portuguesa, mesmo em sua modalidade escrita, como ferramenta na ação mediada, representa um desafio para os alunos surdos, pois a aquisição da linguagem é fundamental para que esses sujeitos possam reescrever-se social, cultural, política e cientificamente (QUEIROZ; BENITE, 2010). Sem língua constituída, como esses sujeitos poderão ser incluídos de forma verdadeira? 


\section{Algumas considerações}

O bilinguismo pressupõe pensar a educação de surdos tendo como sua primeira língua a LIBRAS, e o português como segunda língua. O que podemos perceber, por meio desta análise, é que o bilinguismo é prática que não acontece nas escolas inclusivas pesquisadas, pois a LIBRAS vem adquirindo aspecto secundário na sala de aula. Por outro lado, os alunos surdos não são alfabetizados, não sabem português, e também não dominam a LIBRAS. Assim, sem língua constituída, os sujeitos surdos estão sendo apresentados a conceitos inerentes a uma linguagem simbólica, pelo professor de ciências, mas não estão em contato direto com este membro da comunidade científica, e necessitam do intérprete de LIBRAS para realizar essa intermediação. Porém, não transitam nem em uma linguagem nem em outra, o que compromete o aprendizado de ciências.

Podemos concluir que a maior dificuldade no ensino de ciências para surdos ainda é a barreira linguística. Verificamos que estratégias didáticas que contemplem o aspecto visual aliadas à contextualização do conteúdo são essenciais para a promoção de aprendizado das ciências por esses alunos.

Além disso, mesmo que o surdo tenha domínio da LIBRAS, que deveria ser sua primeira língua, o ensino de ciências é intermediado pelo ILS, que faz uma compreensão do que o professor está ensinando e repassa ao aluno surdo. Então, é preciso também que o ILS compreenda os termos utilizados pelo professor de ciências, ou seja, tenha o mínimo conhecimento específico sobre o conhecimento que está a interpretar/traduzir, a fim de que a mensagem seja a mais fidedigna possível.

Nossos resultados permitem considerar, ainda, que o ensino de ciências só será possível por meio da atuação conjunta entre professor e intérprete de LIBRAS, no planejamento das atividades a serem desenvolvidas em sala de aula, e não somente no desenvolvimento de métodos e técnicas.

Ademais, o intérprete não é professor do aluno surdo e não deve assumir a função de ensinar-lhe ciências. É preciso que o professor de ciências tenha a mínima noção de LIBRAS, para que possa estabelecer contato com o aluno surdo e possa, pelo menos, compreender suas dúvidas. Isso não pressupõe que o professor deve ser intérprete, ou que o intérprete deva ser substituído. Sabemos que o trabalho simultâneo LIBRAS/português é inviável, e que o professor é responsável pelo ensino e aprendizado, e o intérprete pela interpretação/tradução.

\section{Agradecimentos}

À Fundação de Amparo à Pesquisa do Estado de Goiás (FAPEG), ao Conselho Nacional de Desenvolvimento Científico e Tecnológico $(\mathrm{CNPq})$ e à Coordenação de Ensino Especial do Estado de Goiás. E, em especial, aos professores de ciências e intérpretes de LIBRAS, sujeitos dessa pesquisa. 


\section{Referências}

BARDIN, L. Análise de conteúdo. Lisboa: Edições 70, 2008.

BRANDÃO, C. H. (Org.). Repensando a pesquisa participante. São Paulo: Brasiliense, 1984.

CACHAPUZ, A. et al. (Org.). A necessária renovação do ensino de ciências. São Paulo: Cortez, 2005.

CAPOVILLA, F. C. Filosofias educacionais em relação ao surdo: do oralismo à comunicação total ao bilingüismo. Revista Brasileira de Educação Especial, Marília, v. 6, n. 1, p. 99-116, 2000. Disponível em: <http://educa.fcc.org.br/pdf/rbee/v06n01/v06n01a07. pdf>. Acesso em: 22 jan. 2015.

CHASSOT, A. Alfabetização cientifica questões e desafios para a educação. 3. ed. Ijuí: Ed. Unijui, 2003.

HODSON, D. Existe um método científico? Disponível em: < http:/ / disciplinas.stoa. usp.br/pluginfile.php/119170/mod_resource/content/1/hodson2006.pdf $>$. Acesso em: 22 jan. 2015. Traduzido e adaptado de Is there a scientific method? Education in Chemistry, Cambridge, v. 19, n. 11, p. 112-116, 1982.

LACERDA, C. B. F. A inclusão escolar de alunos surdos: o que dizem alunos, professores e intérpretes sobre esta experiência. Cadernos CEDES, Campinas, v. 26, n. 69, p. 163-184, 2006. Disponível em: <http://www.scielo.br/pdf/ccedes/v26n69/a04v2669>. Acesso em: 27 jan. 2015.

Intérprete de LIBRAS: em atuação na educação infantil e no ensino fundamental. Porto Alegre: Mediação: FAPESP, 2009.

Um pouco da história das diferentes abordagens na educação dos surdos.

Cadernos CEDES, Campinas, v. 19, n. 46, p. 68-80, 1998. Disponível em: < http://dx.doi. org/10.1590/S0101-32621998000300007>. Acesso em: 27 jan. 2015.

LORENZINI, N. M. P. Aquisição de um conceito científico por alunos surdos de classes regulares do ensino fundamental. 2004. 156 f. Dissertação (Mestrado em Educação) - Universidade Federal de Santa Catarina, Florianópolis, 2004.

OLIVEIRA, W. D. Sobre a inclusão escolar e o ensino de ciências. In: VILELA-RIBEIRO, E. B.; BENITE, A. M. C. Temas em educação inclusiva: fundamentos para a sala de aula de ciências. Madrid: Editorial Academica Española, 2012. p. 61-74.

OLIVEIRA, W. D.; MELO, A. C. C.; BENITE, A. M. C. Ensino de ciências para deficientes auditivos: um estudo sobre a produção de narrativas em classes regulares inclusivas. Revista Electrónica de Investigación en Educación en Ciencias, Buenos Aires, v. 7, n. 1, p. 1-9, 2012. Disponível em: <http://www.scielo.org.ar/pdf/reiec/v7n1/v7n1a0>. Acesso em: 27 jan. 2015.

QUEIROZ, T. G. B.; BENITE, A. M. C. Ensino de ciências e surdez: esse "outro" na sala de aula. Revista da SBEnBio, Campinas, v. 3, p. 698-709, out. 2010. 
QUEIROZ, T. G. B.; SILVA, D.; MACEDO, K. Ensino de ciências/química e surdez: o direito de ser diferente na escola. In: VILELA-RIBEIRO, E. B.; BENITE, A. M. C. Temas em educação inclusiva: fundamentos para a sala de aula de ciências. Madrid: Editorial Academica Española, 2012. p. 119-130.

SANTANA, A. P. Surdez e linguagem: aspectos e implicações neurolinguísticas. São Paulo: Plexus, 2007.

TEIXEIRA, F. M. Fundamentos teóricos que envolvem a concepção de conceitos científicos na construção do conhecimento das ciências naturais. Ensaio: Pesquisa em Educação em Ciências, Belo Horizonte, v. 8, n. 2, p. 121-132, 2006.

VIGOTSKY, L. S. A construção do pensamento e da linguagem. São Paulo: Martins Fontes, 2000.

Pensamento e linguagem. 2. ed. São Paulo: Martins Fontes, 2003.

VILELA-RIBEIRO, E. B.; BENITE, A. M. C. A educação inclusiva na percepção dos professores de química. Ciência \& Educação, Bauru, v. 16, n. 3, p. 585-594, 2010.

Disponível em: <http://dx.doi.org/10.1590/S1516-73132010000300006>. Acesso em: 27 jan. 2015.

ZABALZA, M. A. Diários de aula: um instrumento de pesquisa e desenvolvimento profissional. Porto Alegre: Artmed, 2004. 